to 250 , plunging this same bar into ordinary cold water reduced its value to $I 30$; thus the mere difference of the normal temperature of the air in the room and water which had been in this room some hours produced $20^{\circ}$ of difference. In fact, I found that the radiant heat from the hand would raise the magnetic value several degrees, and thus nickel may be regarded as a magnetic thermometer far more sensitive than the ordinary mercurial centigrade.

The instrument also measures the electrical resistance of wires or fluids. In order to make it do this we have only to place the resistance to be measured across the two wires of one induction-coil and on the other known resistance units. In this way we can produce a perfect balance, for it then becomes an induction bridge, the results and modes of testing of which are somewhat similar to Wheatstone's bridge.

It measures also the electrostatic capacity of Leyden jars or condensers, and is sufficiently sensitive to appreciate and measure a surface of tinfoil not larger than four inches square, the condenser being simply placed between the wires of one pair of coils, and the disturbance produced being measured on the sonometer.

I could cite many more interesting experiments in other branches of physical research for which this instrument offers a wide field of observation; but my object this evening is neither to broach new theories nor to correlate at present the results obtained with views already advanced by Ampère and others.

My only desire has been and is to show the wide field of research the instrument opens to physical inquirers. I trust that in more able hands it may serve to elucidate many physical phenomena.

\section{ON THE EVOLUTION OF THE VERTEBRATA ${ }^{1}$ III.}

CROCODILIA.-The crocodiles form another group of reptiles which has become isolated from all the contemporary groups or orders. The most perfect antithesis of the bird, the crocodile, is, nevertheless, in essentials, in strict conformity with the bird pattern; or, rather, both it and the bird conform to the pattern of some ideal or vanished reptile.

This likeness can be shown in the body, but it is most evident in the head; although unlike the bird's skull in general specialisation, that of the crocodile is, in all essential respects and in numberless details, like that of a young bird. Compare the strong, solid, and dense skull of the crocodile, with its thick, pitted, and rugose bones, and accurate and dentated sutures, with that of a parrot, a toucan, or a hornbill-scarcely a suture left, the bone looking like polished ivory and the substance so completely spongy within that its weight is but little more than that of a few quills of the same bird. Yet these lightest and most delicate of all skulls had once all the sutures seen in that of the crocodile, and the two types of skull developed each "centre" in the same manner and on a similar model; in the middle of the incubating period they were so much alike that one diagram might have served to illustrate both.

In their covering, as well as in their general form, the crocodiles contrast strongly with the birds; instead of a soft plumage, often gorgeous in colour, they are invested with a coarse armour of segmental rows of rough plates of bone (dermostoses), coated over with horn. Representatives of the turtle's plastron are seen in the socalled abdominal ribs-which must not be confounded with like structures of the same name seen in the chamæleon and Hatteria-and in the inter-clavicle, which is fixed to the under-surface of the breast-bone.

The frame-work of the body is well ossified in the adult, and the vertebræ and ribs are very similar to those

'Abstract of Prof. Parker's Hunterian Lectures, delivered at the College of Surgeons, commencing on February ro. 1 Continued from p. 64 . of a bird, the greatest difference being in the neck, which is much shorter and stouter, and has /much larger rudimentary ribs, which remain permanently distinct. In the young of the Ratite (Emeu, \&c.), however, all the cervical vertebræ except the atlas and axis, have a pair of ribs, which remain distinct for a considerable time in the upper part and permanently in the lower part. The crocodile's sacrum also, instead of being composed of a large number of joints, has merely two, that carry the pelvis, whilst the tail, instead of being arrested, as in living birds, is developed, as in the ancient Archcopteryx. The vertebræ of the crocodile are for the most part procelous (concave in front and convex behind), and thus resemble those of the dorsal region of plovers, penguins, and some other water-birds. The setting in of the ribs and their overlapping (uncinate) processes are also similar to what is seen in birds.

The rhomboidal sternum is cartilaginous, and sends out behind a pair of xiphoid processes, being defended in front by the bony interclavicle, which is the counterpart of the leg of the Y-shaped merrythought of the fowl. The shoulder-girdle is composed of a pair of cartilages with a gentle curve and of a moderate width; each is ossified by two bones, an upper, the scapula, and a lower, the coracoid.

In the head, all distinction between dermal scutes and sub-cutaneous bones is lost; a thick web is ossified throughout, and has only left a thin layer of the skin soft, as a "quick" to the horny coat. From the snout to the exit of the optic nerves, the internal cranium is unossified, while the posterior part is well ossified, as are also the basal region up to the pituitary body, the capsules of the ear, and the alisphenoids. The labyrinth of the nose is very simple. A hard palate is formed by the maxillaires, palatines, and pterygoids, thus causing the nasal passages to open far back in the throat, this specialisation being of advantage to the crocodile while drowning his prey.

The structure of the organ of hearing agrees with that of the tortoises and the higher lizards, the drum cavity being formed inside the quadrate, into which an air-tube (siphonium) opens into the mandible, as in birds. The two drum cavities communicate in a passage running over the skull behind. A rudiment of this passage exists in birds, and in the higher kinds opens into the spongy tissue which lies between the two tables of the skull.

Birds.-The lower tentative forms of birds have for the most part evidently come and gone during the time the crocodiles have been in existence. The palæontologists, however, are beginning to show us how thoroughly intermediate between the true reptiles and birds the extinct birds of the chalk and the oolite were. The most ancient or generalised types of living birds, the ostrich tribe, are all incapable of flight, but the oldest bird known in the fossil state-Archaopieryx - was well fitted for flight.

Interesting connecting links between the ostrich tribe and the higher forms are seen in the southern world (Notogoea), where many of the birds have a much lower and more reptilian structure than their northern relatives, their power of flight being less, their brain smaller, and in many cases they are deficient in the inferior larynx or syrinx. Thus the South American Tinamous, which are intermediate between the ostrich tribe and the grouse, have a very small brain, and consequently such low intelligence that they have not the sense to use their own wings; moreover, their flesh resembles that of a reptile, they possess lacertilian super-orbital bones, and a considerable number of the sutures in the head remain permanently open. These birds do not so much resemble the South American Rhea as the Australian Apteryx, representative species being often found in these two regions which correspond with each other, but are far more ancient than, and do not correspond with, the types found north of "Wallace's Line." 
The influence of desert or prairie life has doubtless had much to do with the modifications found in the ostrich tribe ; the principal of these modifications are, the abortion of the tail, the lessening of the wing, the huge increase in the size of the hind-limbs, and the suppression of unnecessary toes.

It is quite within the bounds of reasonable conjecture to suppose that from time to time great waves of morphological force, so to speak, and fresh revivals of life, passed over the old reptilian fauna, and that many kinds of the more ductile reptiles yielded to the influence of these waves. When, however, one member improved, the other members improved with it; the loss of digits and their claws, the sport that appeared in the exchange of feathers for scales, the increased solidity of the sacral region, and the tighter setting on of the hind limbs-these were only a few of the things that were correlated in this radical reform of the old reptilian types. The teeth were only slowly lost, as the invaluable papers of Prof. Marsh show. Epidermal imitations of teeth, however, occur in existing ducks and geese, and in the South American Passerine, Phytotoma rara, in which latter they are ossified from the jaw.

The hot condition of the bird's blood has much to do with the intensity and rapidity of its early metamorphosis. The time in which arboreal birds (Altrices) are ripened for hatching is marvellously short, and after this, in a single month, many of them have learnt their lesson in flying, and begin to be ready to migrate.

The segmented form of the simpler fish, or amphibian, is still to be traced in the bird. The embryo of the swan develops six dozen segments behind the head, twentyfive of which belong to the neck. Most of these segments can be traced in the adult, except those of the tail, the posterior ten of which, though separate at the time of hatching, grow together to form the plough-share bone, on which the tail-quills are set.

The endo-skeleton is greatly developed, and its ossification is carried to the utmost degree of perfection, only traces of cartilage persisting in the joints and often in the nose.

The outer skeleton may be divided into three categories. The first of these consists of the exuberant and unique growths of the epidermis - the feathers and quills, to which must be added the horny sheaths of the beak and the scaly coverings of the legs. The second consists of the overlapping series of cartilages that become ossified to form the limb-girdles from which the limbs grow out, and also a pair of sub-cutaneous cartilages in front of the head, which belong to the labial category, and sometimes there is one on each ramus of the mandible. The third takes in the sub-cutaneous bones that invest the proper endo-skeleton, whether bony or cartilaginous, and the ossified tendons and fasciæ (aponreuroses). There are three proper investing bones, as a rule, attached to the shoulder-girdle, which coalesce to form the greater part of the merrythought (furcula); these, as before mentioned, are the counterparts of the ventral splint-bones of Plesiosaurus and Hatteria, and their non-coalesced representatives are also seen in lizards and in the Monotremes. In the head there is a large number of investing bones, which, however, enjoy for the most part a very temporary independent existence.

The increased size of the brain-mass has given rise to a very different proportion of cranial to facial elements as compared with what exists in the reptile, and the process of ossification is carried to its utmost perfection. Except at the articular extremities of the bones, all the original cartilage rapidly disappears; this matrix is succeeded by marrow, which is in many cases completely absorbed, giving rise to air-cavities, which open into the nearest air-sac.

The endo-skeletal palatine bones are ossified to a great extent whilst the tissue is still formed of young and soft cells, before the solid hyaline cartilage has had time to grow, and in many passerine birds the exo-skeletal vomers are grafted upon a pair of cartilages, which, however, also belong to the outer skeleton. No true cartilage has yet been found in the outer ear. Rudiments of the byoid and first branchial arch exist behind the lower jaw.

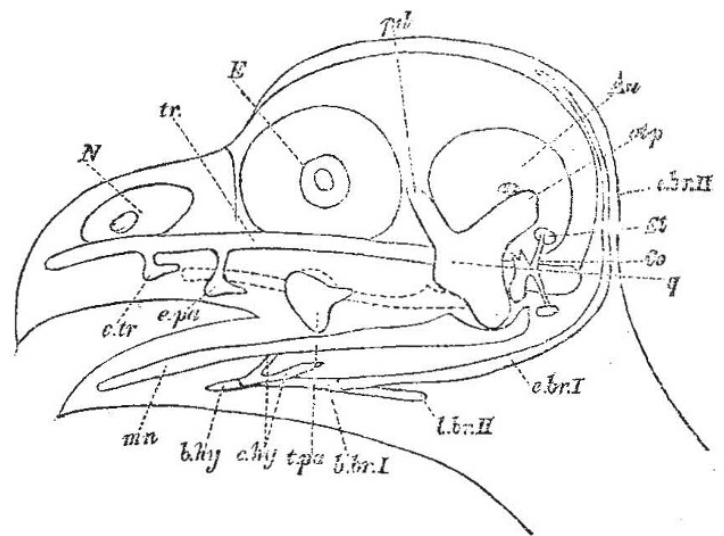

Diagram of the Chondrocranium of a Passerine Bird. au, auditory capsule; b.br, basi-branchial; $b . h y$, basi-hyal; $c . h y$, cerato-hyal; c.br, ceratobranchial; $c o$, columella; c.tr, cornua trabeculæ; $\mathbf{E}$, eye; $e . b r$, epibranchial ; e.pa, ethmo-palatine; $m n$, mandible; $N$, nasal capsule ; ot. $p$, otic process; $q$, quadrate; st, stapes; t.pa, trans-palatine ; $t r$, trabeculæ

The protrusible and retractile face of the bony fishes is constructed in a manner very similar to that seen in the hinged fore-face of a fowl or parrot; in these birds, as in the fishes, the pre-maxillaries push the maxillaries aside, cover them over, and keep them from the dentary edge, thus converting the bones usually so massive, into feeble "moustache bones" (ossa mystacea, Cuvier).

Mammals. - Such a hypothesis as that Nature bred either all her birds or all her mammals from one stock is at once upset by the facts presented by the structure of the lowest mammals-the duck-billed platypus and the echidna. Between the mammals and the types which foreshadow them, viz., the Selachians and the Batrachians, there is unfortunately a large chasm; and moreover, the platypus and echidna refuse to lie fairly in the direction indicated at the top of this chasm, as they confusingly partake of the characters of the reptile and bird; as well as those which are peculiarly mammalian.

The skeletal parts of the mammal are modified in a great number of ways answering to the great variety of their modes of life, and especially in regard to prehension and progression. In the higher kinds there are few or no subcutaneous bones (parostoses) in the body, but the head depends upon these for its construction as much as in the birds: where there are no clavicles there are no parastoses behind the head.

In the lowest forms (platypus and echidna) there are three clavicular bones; in the pangolin (one of the Edentata) the body is covered with large imbricated scales; the armadillos have strong body armour, which is both bony and horny, as in the tortoises and crocodiles, and in certain rodents, such as the South American Cologenys and Lophiomys imhausii, the bones of the head resemble very much the bony scutes of the lower types, for they become granular and almost ganoid on their outer surface. The endoskeleton and the overlying limb-girdles and limbs are developed to a perfection peculiar to the mammal, the culmination of which is seen in our own species.

Above the lowest forms, neither in the low marsupials nor in the almost equally low Edentata, do we find the middle collar-bone (inter-clavicle). Moreover, in the large Herbivora with a keeled chest, the paired clavicles also disappear; in man, monkeys, bats, moles, and shrews, 
they have their largest development, but do not correspond merely to the paired bones of the lizard and platypus, being formed both of cartilage and bone as in the bird. The girdle of the hind-limb is of a more archaic and less metamorphosed pattern than that of the fore-limb; in man the pelvis corresponds very closely with the shouldergirdle of the frog. The limbs agree nearly with the tailed amphibian pattern. The main modification of the spine is seen in the presence of inter-central pads or buffers of cartilage, and a pair of bony epiphyses to each centrum.

The skull is wrought into one strong, compact building, and the short, solid, lower jaw is articulated directly to the head; the primary lower jaw stops growing at a very early period of embryonic life, and then loses, by absorption, the Meckelian rod, which is, indeed, all the arch except its upper part; the working mandible is formed from superficial bone and cartilage, the prototypes of which must be sought amongst the lowest fishes. The upper part of the primary mandibular arch, which in the lower types gives rise to the quadrate, is now specialised to form the malleus, or the outermost bone of the chain of the middle ear. One principal external bone and sometimes an imperfect rudiment of one or two others appears on the inside of the primary lower jaw in the embryo, but these enjoy a very short separate existence. In the hyoid arch the upper element, or epi-hyal, is divided off to form the incus, the middle bone of the middle ear. The orbiculare is a further subdivision of the upper element, and the stapes is a part of the auditory capsule segmented off. The cochlea, which, in the Sauropsida, forms only part of a coil, is now perfected into a spiral chamber with several turns. The membrane of the drum lies at the bottom of a long tube, and is there stretched upon a bone which at first is a mere imperfect ring, but which afterwards grows out as the bony meatus externus. The concha auris is an opercular cartilage of the first cleft, the essential part of which is the tragus.

Outside the primary lower jaw, the two halves of which are confluent in front and below, there is a cartilage having the same relations as the labial of a shark; in the outside of this cartilage the dentary splint bone appears, and gradually converts it into bone, from before backwards. Throughout life part of this cartilage still remains, capping the convex hinge of the lower jaw; it is probable that the cartilaginous plate within the joint (menisc2is) and the cartilage lining the temporal bone above, to finish the joint, are derived from the same source.

As already mentioned, the forecast of the mammalian type, which is very plain in the cartilaginous fishes, becomes much more plain, definite, and indubitable in the frog and toad. In fact, the building materials are passed from hand to hand, as it were, in this way: the batrachian forefathers brought down all things meet for the work, borrowing and taking cartilages from the Selachians, and bones from the Ganoids, and noiselessly forming them, after due selection, into a new, more compounded, and nobler structure.

The rude ancestors of the tribes that give suck began to build on this higher level, with these more varied or better-shaped blocks and plates; and by the infinite cunning, the effectual working of the morphological force, in due time the consummation was effected of vertebrate form. But the consummation of all, the election and selection, that has been going on since the beginning of the ages, is seen in man, who alone gives meaning to, and reads the meaning of, the whole mystery of organic
life.

OUR ASTRONOMICAL COLUMN

THE OBSERVATORY OF MANNHEIM. - We have received from Prof. Valentiner, the successor of Prof. Schönfeld in the direction of the observatory at Mannheim, the third part of the "Astronomical Observations" issued from this establishment. The two former parts, published in I 862 and 1875 , contained observations of nebulæ and clusters, but without micrometrical measures of the positions of the components of the latter objects; in the present part the two clusters Nos. I I66 and 4410 of Sir John Herschel's General Catalogue are specially treated upon, and the position of thirty-six stars in the former cluster and seventy-one stars in the latter have been determined by micrometrical reference to a number of stars the places of which have been fixed by meridian observations. In this work a filar-micrometer upon the Steinheil refractor has been employed, and both observations and reductions have been made with every care to secure a high degree of precision. Diagrams of the stars observed in each cluster are appended. It is intended. to measure the clusters I454 and III9 of the General Catalogue in the same manner. Only by patient and accurate measures of this nature can we hope eventually to learn the internal structure of these systems. Prof. Valentiner has given full details of his observations and reductions, which may be advantageously consulted by any one proposing to enter upon similar work. The Mannheim Observatory not possessing a meridian-circle, he has had recourse to the assistance of other observatories-Berlin, Leyden, and Leipsic-for the accurate determination of the positions of his reference-stars.

TEMPEL'S COMET.-M. Raoul Gautier has circulated an ephemeris of this comet, founded upon a correction of his predicted elements from three observations by Dr. Tempel at Arcetri. The positions for May do not materially differ from those which have appeared in NATURE. The corrected orbit is as follows :-

Perihelion passage 1879 May $7^{\circ} \mathrm{O} 2$ M.T. at Berlin.

Longitude of perihelion ... 238 in $3^{\prime \prime} \cdot 1$ ) From mean equinos

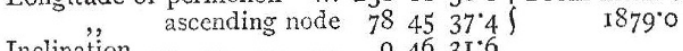

$\begin{array}{lllllllll}\text { Inclination } & \ldots & \ldots & \ldots & \ldots & 9 & 46 & 3 \mathrm{I}^{\circ} 6\end{array}$

$\begin{array}{llllll}\text { Angle of excentricity } \ldots & \ldots & 27 & 35 & 0^{\circ} 6\end{array}$

Mean daily motion $\quad \ldots . . . . \quad 593^{\prime \prime} \cdot 18$

Log. semi-axis major ... ... 0.517880

THE Minor Planets.-From the Berliner Astronomisches Jahrbuch for 1881 , which is just published, it appears that of the 194 small planets discovered up to the end of March last, eighteen have been observed at only one opposition, one of the number being Medusa, which, if the elements so far determined can be relied upon, has a shorter period of revolution than any other member of the group, Flora coming next. Upwards of 150 pages are devoted to the elements and ephemerides of these bodies for 1879 , forming the speciality of this publication, upwards of forty calculators in various parts of Europe and America taking part in this laborious work; seventy-one of the ephemerides are by Dr. Maywald, of Berlin, who has been long similarly occupied. As already stated this portion of the Berliner Jahrbuch has been sent out to observers in anticipation of the appearance of the volume. The circulars independently issued by Prof. Tietjen have kept astronomers informed as to elements and positions of the newly-discovered bodies.

Prof. Peters, of Clinton, New York, announces his detection of a planet which, if new, will be No. 196.

The OCCultation of Venus on August 20.-On this date Venus, then at her greatest brilliancy, and so of crescent-form, will be occulted by the moon, which is also a narrow crescent at the time. The phenomenon would be one of much interest were it not that it is visible in a dark sky, only in the South Atlantic. If we calculate for the Royal Observatory, Cape of Good Hope, we find that the immersion takes place at $8 \mathrm{~h}$. $44 \mathrm{~m}$. mean time, but the planet will have set about five minutes previously, and in other parts of the South African Colonies, the occultation is similarly invisible. At St. Helena there will be no occultation. 